\title{
LEUCEMIA LINFOIDE AGUDA Y MAL DE POTT: RESPUESTA PARADÓJICA AL TRATAMIENTO ANTITBC
}

\author{
Carlos Hernando Gómez MD*, Viviana Vargas MD**, Camilo Andrés Alfonso MD**, Leonidas Vásquez MD**, \\ Claudia Patricia Casas MD***, Virginia Abello MD****, Adriana Jiménez MD*****
}

\section{Resumen}

Hombre de 58 años con diagnóstico de leucemia linfoide aguda llevado a trasplante de progenitores de sangre periférica de donante intrafamiliar. Requirió manejo inmunosupresor por presencia de enfermedad injerto contra huésped aguda y crónica. Consultó por dolor lumbar severo y en los exámenes se encontraron lesiones compatibles con espondilodiscitis L4-L5 y colecciones paravertebrales. Con sospecha de tuberculosis se inició tratamiento empírico, la evolución clínica inicial fue tórpida por persistencia de síntomas y compromiso neurológico progresivo, por lo cual se sospechó presencia de micobacterias atípicas vs resistentes. Se logró aislamiento de Mycobacterium tuberculosis susceptible a la terapia instaurada. Se continuó esquema de tratamiento TBC con evolución clínica a la mejoría. Se interpretó como reacción paradójica a la terapia, pero con presencia de lesión renal en la que se confirmó recaída de la enfermedad hematológica.

Palabras clave: tuberculosis, Mycobacterium tuberculosis, trasplante de médula ósea, síndrome inflamatorio de reconstitución inmune.

Abreviaturas: TBC, tuberculosis.

\section{ACUTE LYMPHOID LEUKEMIA AND POTT DISEASE: PARODIXICAL RESPONSE TO ANTI-TB TREATMENT}

\section{Abstract}

We report the case of a 58 year-old male patient diagnosed with acute lymphoid leukemia who received a peripheral blood stem cell transplant from a family member. He required immunosuppressive management for developing acute and chronic graft-versus-host disease. He presented with severe back pain. Imaging showed spondylodiscitis L4/L5 and paravertebral fluid collections. Empirical anti-TB therapy was instituted for suspicion of tuberculosis. The initial phase was torpid due to persistent symptoms and progressive neurologic compromise, thus, the presence of atypical vs resistant mycobacteria was suspected. Initiated-therapy-susceptible Mycobacterium tuberculosis was isolated. The antiTB therapy regimen was continued with improvement in his clinical state. It was interpreted as a paradoxical response to therapy, associated with the presence of a renal lesion in which a relapse of the hematologic condition was confirmed.

Key words: tuberculosis, Mycobacterium tuberculosis, bone marrow transplant, immune reconstitution inflammatory syndrome

Fecha recibido: diciembre 15 de 2014 - Fecha aceptado: mayo 7 de 2015

* Unidad de prevención y control de infecciones, Hospital de San José, Bogotá DC, Colombia.

** Residente III de Medicina Interna. Fundación Universitaria d Ciencias de la Salud. Bogotá DC, Colombia.
*** Hematóloga, Hospital de San José. Instructora Asociada. Fundación Universitaria de Ciencias de la Salud. Bogotá DC, Colombia.

**** Hematóloga, Hospital de San José. Instructora Asistente. Fundación Universitaria de Ciencias de la Salud. Bogotá DC, Colombia.

****** Profesora Asistente. Fundación Universitaria de Ciencias de la Salud. Unidad de Prevención y control de infecciones. Hospital de San José. Bogotá DC, Colombia. 


\section{Introducción}

Los pacientes con neoplasia hematológica son un reto para el proceder diagnóstico ya que las manifestaciones clínicas pueden presentarse en forma variada. El trasplante de progenitores de donante no relacionado puede conllevar a manejo inmunosupresor a largo plazo. La TBC debe ser considerada como probabilidad diagnóstica en zonas de alta prevalencia, sin embargo el índice de sospecha es de suma importancia pues los estudios confirmatorios pueden tardar un tiempo muy valioso antes de que el paciente reciba tratamiento si el enfoque no es el apropiado.

\section{Caso clínico}

Hombre de 58 años con diagnóstico de leucemia linfoblástica de precursores B (LLA) de alto riesgo por edad, quien recibió quimioterapia con esquema $\mathrm{Hy}$ perCvad por seis ciclos. Se consolidó con trasplante alogénico de precursores hematopoyéticos de donante idéntico intrafamiliar en la primera remisión completa. Presentó enfermedad injerto contra huésped aguda grado II en piel y de tipo crónica severa en piel e hígado, motivo por el que requirió manejo inmunosupresor.

Ingresó el mes quince postrasplante por síntomas de cuatro meses de dolor en región lumbar irradiado a pierna derecha que aumentaba con el ejercicio, sin parestesias ni alteración en la fuerza, motivo por el cual se hospitalizó y se practicó resonancia magnética de columna lumbosacra, que demostró edema de los cuerpo vertebrales L4 y L5 y al lado izquierdo colección de tipo absceso loculado pre y paravertebral bilateral (Figura 1)

Por los hallazgos y ante la sospecha de mal de Pott se realizó biopsia guiada por TAC de masa paravertebral, con estudios de PCR para M. tuberculosis. Ante la posibilidad de TBC espinal en paciente inmunosuprimido se inició tratamiento empírico. A pesar del manejo presentó aumento de los síntomas, por lo que consultó un mes después. Se realizó nueva RM con evidencia de una colección liquida que desplazaba el disco intervertebral, con reducción de la amplitud del canal medular y compromiso de las raíces, así como dos abscesos tabicados paraespinales y otro en el psoas, por lo que se cuestionó que fuera Mycobacterium tuberculosis el agente etiológico dada la escasa respuesta.

Presentó episodios de mejoría parcial con recurrencia de los síntomas por dolor y signos de respuesta inflamatoria sistémica. Se repitieron los estudios imaginológicos con hallazgos de lesiones loculadas, por lo que se realizó drenaje quirúrgico y tratamiento antibiótico con piperacilina/tazobactam y vancomicina por sospecha de etiología piógena, sin ninguna mejoría clínica ni paraclínica demostrable.

El paciente cursó con estreñimiento, incontinencia urinaria y disestesias considerados como secundarios a mielopatia compresiva. Se decide nuevo estudio de RM de columna que muestra la reducción de la luz del canal medular con efecto compresivo sobre el sacro y raíces L4 y L5, con material hiperintenso en regiones paravertebrales que infiltran músculos psoasiliaco del lado derecho, sacro y L3.

Fue llevado a cirugía que evidenció membranas fibrinopurulentas y aumento en la densidad del riñón del cual se toma biopsia con informe de patología compatible con lesión tumoral sospechosa de neoplasia hematolinfoide y la inmunohistoquímica confirma un linfoma linfoblástico de precursores B. Se reinició tratamiento TBC tetraconjugado (isoniazida, rifampicina, pirazinamida y ethambutol), con aislamiento microbiológico en líquido paravertebral de Mycobacterium tuberculosis y PCR para este germen positivo para $h s p$ 65 , con posterior control del dolor y estabilidad del cuadro neurológico. Se consideró que la respuesta inicial fue debida a reacción paradójica del tratamiento, con estudios de susceptibilidad antituberculosos que demuestran perfil de resistencia habitual.

\section{Discusión}

La TBC es la segunda causa de mortalidad de origen infeccioso en el mundo después del SIDA, cada año diez millones de personas son infectadas de las cuales $95 \%$ corresponden a países en desarrollo y cerca de dos millones mueren al año por dicha condición. 


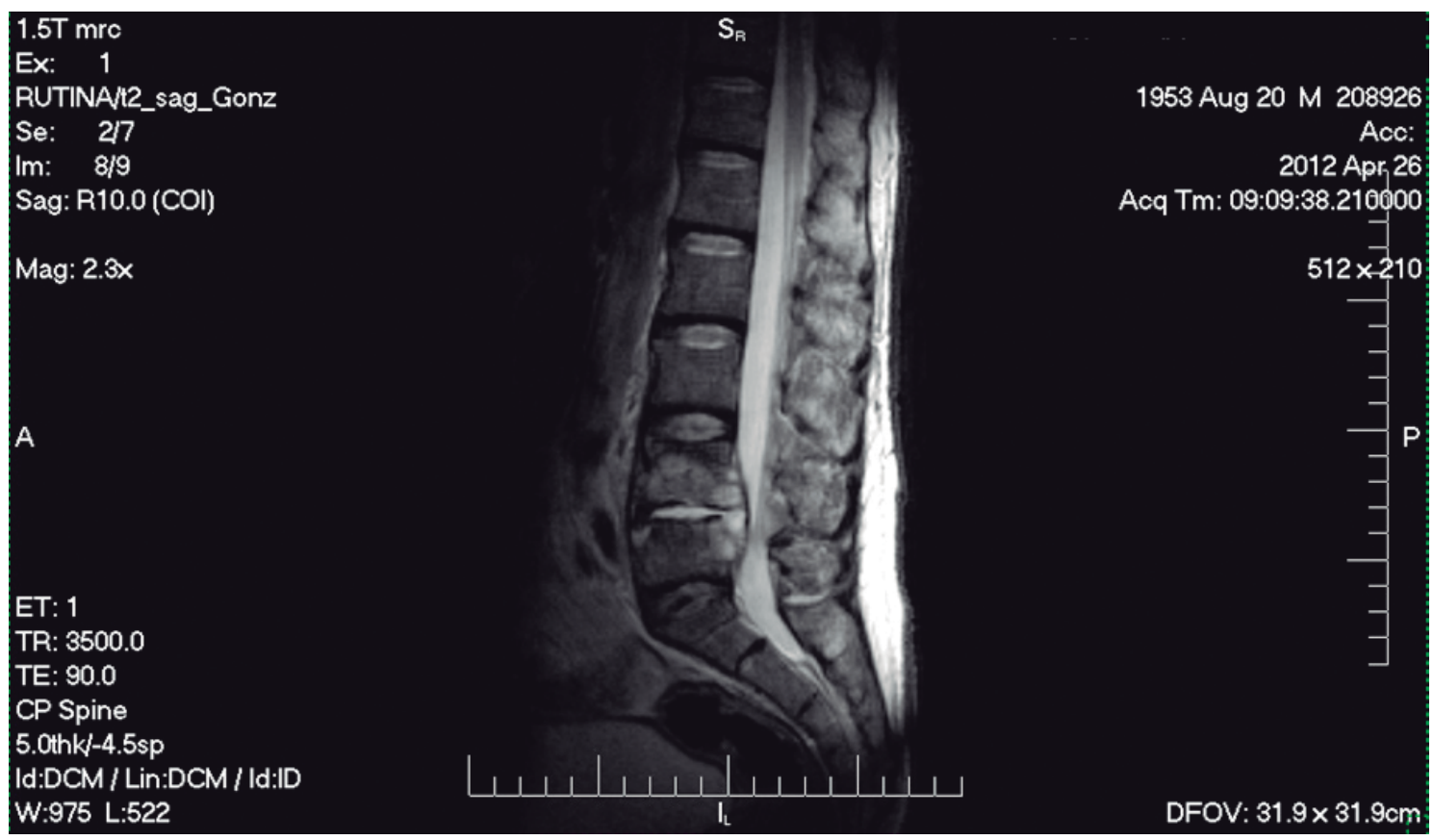

Figura I.Edema de los cuerpos vertebrales L4 y L5 con disminución de la altura del espacio intervertebral, edema del disco central y al lado izquierdo colección-absceso loculado pre y paravertebral bilateral.

El incremento en la incidencia se ha relacionado con varios factores como la mayor expectativa de vida en pacientes con enfermedades crónicas y en postrasplantados. ${ }^{1}$ El compromiso de la columna vertebral se reporta solo en un 3 a $5 \%$ de todos los casos de TBC en general y la micobacteria se asienta allí tras diseminación hematógena. Los síntomas iniciales son de carácter inespecífico como malestar general, sudoración nocturna, fiebre, pérdida de peso, siendo el dolor el síntoma más importante que aparece en forma tardía luego del colapso de los cuerpos vertebrales. ${ }^{1}$

Los pacientes postrasplante de medula ósea son un grupo de alto riesgo para la reactivación de TBC por varias razones: depleción de la inmunidad celular mediada por células $\mathrm{T}$ por uso de terapias inmunosupresoras (en especial corticoides), altas dosis de quimioterapia, enfermedad injerto contra huésped (GVHD) y la radioterapia corporal total. Luego del trasplante la forma de presentación de la TBC es la reactivación de una infección latente. La epidemiología es poco conocida aunque algunos datos aportados por series de casos demuestran incidencias bajas. En Norteamérica se reportan 5,1 casos de TBC por cada 100.000 pacientes postrasplante de medula ósea. ${ }^{2}$ Akan y col. en un revisión sistemática de 56 pacientes con dicha complicación encontraron que la localización más común de reactivación de TBC en estos casos es pulmonar (84\%), seguida por el sistema nervioso central $(7,4 \%)$, medula ósea $(3,7 \%)$ y ganglionar $(1,8 \%)$, siendo menos frecuentes las extrapulmonares. El diagnóstico se realizó por cultivo en un $60 \%$, seguido por hallazgos histopatológicos $(20 \%)$ y en orden de frecuencia tinción directa y PCR. El 91\% de los casos se documentó en el periodo postrasplante, solo en 7,4\% el diagnóstico se realizó previo al trasplante de medula ósea, con tasas de curación de la infección de $77 \%$ en esta serie. ${ }^{2}$ La mortalidad en pacientes con TBC y trasplante alcanza el $30 \%$ y es más frecuente en los pacientes con rechazo del injerto. ${ }^{2}$

El deterioro clínico después de iniciar la terapia TBC es un fenómeno descrito en varios escenarios clínicos y tiene una posible explicación por el daño inmunológico asociado con la severidad de la afección predisponerte. Se define como el empeoramiento clínico o radiológico de lesiones por TBC preexistente a la aparición de nuevas lesiones con una respuesta clínica inicial favorable. El diagnóstico se establece una vez que se han podido descartar otras situaciones como la presen- 
cia de infección asociada con el cuidado de la salud, resistencia a la medicación $\mathrm{TBC}$, pobre adherencia a la terapia y efectos adversos a la medicación. ${ }^{3} \mathrm{La}$ descripción de la respuesta paradójica ha sido mejor expuesta en pacientes con coinfección por virus de la inmunodeficiencia humana (VIH) y menos reportada en otros tipos de condiciones médicas. La explicación mejor aceptada es la interacción entre la respuesta inmune del huésped y el efecto directo de productos mico-bacteriales. ${ }^{4}$ La TBC activa puede deprimir las respuestas de hipersensibilidad de tipo tardío. Este fenómeno incluye activación de monocitos por proteínas derivadas de las micobacterias, que conduce a un incremento de la producción de interleucina 1 que suprime las respuestas inmunes y de antígenos específicos del bacilo TBC, que conlleva a la producción de concentraciones inmunosupresoras de prostaglandina E2. Una vez que la TBC está controlada y la inmunosupresión resuelta, se incrementan las respuestas de hipersensibilidad de tipo tardío que conducen a activar y acumular linfocitos y macrófagos en el sitio del depósito bacilar o producir toxinas cuando el bacilo muere. Si la activación ocurre en un foco microscópico del sistema nervioso central aparecerán tuberculomas ${ }^{4}$ y si ocurre en un tuberculoma, este puede aumentar su tamaño, debido al desarrollo de focos presentes antes del inicio de la terapia que por disturbios inmunológicos desarrollaron la infección focal en lugar de controlarla..$^{5-7}$

Cheng y col. ${ }^{8}$ en una revisión sistemática de la literatura en Medline de 1966 a 2001 encontraron reportes de 143 casos de reacción paradójica al tratamiento TBC en pacientes sin VIH. La relación de hombre/ mujer fue de 1,2/1. El 46,7\% de los casos correspondió a pacientes de origen asiático, en el 17\% de los episodios descritos se realizó primero el diagnóstico de TBC pulmonar y las formas extrapulmonares las más asociadas con pacientes no VIH $(82,8 \%)$. En la mayoría de los casos el compromiso del SNC se expresa en forma de tuberculomas con signos de focalización neurológica (parálisis de nervios craneales, disfunción motora, sensorial, cerebelosa) y convulsiones; es posible que exista un sesgo en las publicaciones por el hecho de tratarse de una forma grave. La presencia de Mycobacterium tuberculosis fue confirmada por cultivo en $40,2 \%$ y hasta en $24 \%$ la tinción de $\mathrm{ZN}$ en el examen directo fue positiva. Después de la reacción paradójica neurológica la siguiente es el tracto respiratorio y luego se describen localizaciones tan diversas como el espacio pleural ${ }^{9}$, mediastino o la aparición de abscesos "fríos" en la piel. La persistencia de fiebre se reportó hasta en $13 \%$ de los casos como hallazgo clínico. El tiempo promedio para la aparición de la respuesta paradójica fue de 60 días desde el inicio de la terapia TBC y el tratamiento de elección fue esteroides en $39 \%$ y manejo quirúrgico hasta en el $60 \%$ de los casos reportados. El 77\% se resolvió en forma espontánea con la continuación de la terapia TBC.

La respuesta paradójica al tratamiento antiTBC se reconoce como un fenómeno no infrecuente, las series lo reportan entre 6 y $30 \%$ y aunque existe una mayor tendencia a comprometer el SNC, cerca del $50 \%$ de los casos son de localizaciones diversas ocupando el segundo lugar el compromiso pleural. Los dos marcadores predictores de respuesta paradójica demostrados en las diferentes series son la recuperación en el recuento leucocitario y la positivizacion de la PPD (esta ultima no fue realizada en el paciente reportado). La severidad del cuadro clínico está relacionada con el grado de recuperación inmunológica. Una respuesta inmunológica exagerada conlleva la presencia de lesiones más severas e incremento en la mortalidad. El uso de esteroides parece seguro como terapia coadyuvante. ${ }^{9}$ Está menos estudiado el uso de otros medicamentos como pentoxifilina o talidomida que se han documentado efectivos solo en reportes aislados.

Nuestro caso demuestra la presencia del fenómeno de respuesta paradójica al tratamiento TBC en un escenario poco frecuente como es el postrasplante de medula ósea y hasta donde sabemos la TBC espinal no ha sido informada como parte esta reacción paradójica $^{7}$, que debe contemplarse una vez se descarten otras infecciones oportunistas, falla en la adherencia al tratamiento o resistencia a la terapia TBC. 


\section{Referencias}

1. Cheung WY, Luk KD. Clinical and radiological outcomes after conservative treatment of TB spondylitis: is the 15 years' follow-up in the MRC study long enough?. Eur Spine J. 2013 Jun; 22 Suppl 4:594-602.

2. Akan H, Arslan O, Akan OA. Tuberculosis in stem cell transplant patients. J Hosp Infect. $2006 \mathrm{Apr} ; 62(4): 421-6$.

3. Cheng VC, Yuen KY, Chan WM, Wong SS, Ma ES, Chan RM. Immunorestitution disease involving the innate and adaptive response. Clin Infect Dis. 2000 Jun; 30(6):882-92.

4. Chambers ST, Hendrickse WA, Record C, Rudge P, Smith H. Paradoxical expansion of intracranial tuberculomasduring chemotherapy. Lancet. 1984 Jul 28; 2(8396):181-4.
5. Malik GM, Mubarik M, Basu JA, Kadla SA, Hussain T, Rashid S. Paradoxical expansion of cerebral tuberculomas during therapy for Pott's spine. J R Soc Med. 1996 Nov; 89(11):643-4.

6. Al-Majed SA. Study of paradoxical response to chemotherapy in tuberculous pleural effusion. Respir Med. 1996 Apr; 90(4):211-4.

7. Lizarazo J. Aparición paradójica de tuberculomas encefálicos durante el tratamiento de tuberculosis en pacientes inmunocompetentes. Biomédica. 2004; 24(Supl.): 34-42.

8. Cheng VC, Ho PL, Lee RA, Chan KS, Chan KK, Woo PC, et al. Clinical spectrum of paradoxical deterioration during antituberculosis therapy in non-HIVinfected patients. Eur J Clin Microbiol Infect Dis. 2002; 21(11): 803-9.

9. Bukharie H. Paradoxical response to anti-tuberculosis drugs: resolution with corticosteroid therapy. Scand J Infect Dis. 2000; 32(1):96-7. 